\title{
Research on Pricing Policy of E-business Supply Chain Based on Bertrand and Stackelberg Game
}

\author{
Qian Chen*, Chuanxu Wang and Changyan Xu \\ School of Economics and Management, Shanghai Maritime University, Shanghai \\ 201306, China \\ *qianchen@shmtu.edu.cn
}

\begin{abstract}
As a new marketing way, more and more enterprises begin to pay more attention to the direct marketing channel, in order to gain more market share and economic profit. In this paper, we introduced two parameters into to the pricing model of e-business supply chain, as direct channel service level and retail channel service level. Then construct the pricing model under stackelberg game, bertrand game and centralized decision mode. Through the comparison and analysis of the pricing models under different decision-making environment, we get the pricing strategy that manufacturers and retailers should take when they make service cooperation. Because manufacturers always get more profits in the stackleberg game, so manufacturers tend to choose the stakelberg game with the retailer.
\end{abstract}

Keywords: E-business, supply chain, pricing strategy, stackelberg game

\section{Introduction}

With the rapid development of e-commerce market, more and more enterprises in the traditional retail channels based on the introduction of direct sales channels, in order to gain more market share and greater economic profit. However, the opening of direct sales channels will also face many difficulties. The empirical study shows direct sales channels, service quality has become a serious impact on consumer online shopping factors, and retailers have to directly face the customer, service and low cost advantages, manufacturers of direct sales channels for the service at a disadvantage, manufacturers how to do a good job and retailers into service cooperation has become the focus on the problem [1]. On the other hand, the introduction of direct sales channels, retailers will pose a threat to the retail channels, resulting in channel conflict. Therefore, how to develop a reasonable price, to coordinate the interests of channel members, but also has become an urgent problem to be solved. Speed is gradually slowing growth in Internet users, online shopping is still showing rapid growth momentum, for stimulating national economic development, consumption has become increasingly prominent and direct sales channels is to become an important way to promote consumption[2]. In addition, mobile online shopping becomes important driving force to promote the direct channel sales. Users purchase capabilities continue to improve, direct channel users shopping habits gradually formed and combined with social shopping continue to promote direct sales channels continue to mature, low-cost direct sales channel sales promotion also promote sales of direct sales channels, promote user scale of direct sales channels to accelerate growth.

Although, with the development of the network, the advantages of direct selling channels gradually highlights, but retail channels will not be eliminated, retail channels in the process of selling products still have the advantages of direct sales channels do not have: retailers can collect customer information, product promotion, sales support to meet customer needs and establish the brand effect. Direct marketing channels in the 
development of just started, it is very difficult to do these, will cause the manufacturer's profits and market share has been seriously lost. To sum up, the reservation of direct sales channels and retail channels to expand market share is favorable. Although the introduction of direct sales channels in the traditional retail channels are likely to cause conflicts between the channels [3]. But as long as the coordination of the interests between the two channels, can make the overall efficiency of the supply chain to improve the efficiency of channel members to increase profits. Also, customer preferences are diverse, not a single channel, two channels can bring more shopping options for customers, therefore, the coexistence of two channels can bring more market share. Most enterprises in the opening of direct marketing channels, and will not eliminate the retail channels, tend to sell goods through direct sales channels and retail channels. The research hypothesis of this paper is also based on the coexistence of direct marketing channels and retail channels, and the existence of channel conflict situation.

\section{Literature Review}

\subsection{Logistics Service Quality}

According to the survey of China internet information center, customers' satisfaction on the quality of network goods, logistics distribution and after-sales service is the lowest. In addition, the cost of services has become a bottleneck in the development of direct marketing channels. Among them, due to the goods and the picture does not match the most, to reach $49 \%$; followed by fake and shoddy goods, reaching $23.3 \%$; logistics and distribution time is too long lead to customer satisfaction as high as $49.2 \%$. Thus, the quality of service issues has become an important factor affecting the purchase of customers [4]. Direct marketing channels and retail channels of service differences are mainly reflected in: first, the difference in the quality of goods. Customer through direct channels buy goods, products and network picture is not consistent, and in retail stores, customers can through Purchasing Guide to explain or personally try, probation, more accurate judgment merchandise is not in line with their needs [5]. Second, logistics distribution time difference, customers through direct channels to buy goods need a certain logistics delivery time to receive the goods, and in the retail stores, customers can only pay the money can take away their goods. Third, the difference of after-sales service, direct sales channels to provide after-sales service for customers will bring inconvenience, and consumers can go directly to the annex of the retail store, immediately get the appropriate sales service.

Therefore, retailers have to directly face the customer, service and low cost advantages, manufacturers of direct sales channels for the service at a disadvantage, manufacturers how to do a good job and retailers for service cooperation has become the focus on the problem. Second, the problem of dual channel conflict, manufacturers in the original retail channels based on the opening of direct sales channels, will inevitably occupy the market share of retail channels, the threat of retail channels, resulting in channel conflict. Webb of dozens of manufacturers of the survey results show that $66 \%$ companies believe that the opening of direct channels will lead to the conflict between the two channels [6]. Alba that the introduction of direct sales channels manufacturers will lead to the transfer of retail channels to consumers to direct channels, channels in order to compete for the target customers cause conflicts. When there is a conflict between the two channels, the interests of manufacturers and retailers as well as the relationship of cooperation are damaged. Lead to the important cause of channel conflict is mainly selling price and retail price, direct prices tend to be lower than the retail price and retailer that direct sales channels in the market share, pricing and profit pose a threat, so double channel competition mainly between selling price and retail price competition, price is an important cause of dual channel conflict. Therefore, in the dual channel supply chain environment, manufacturers 
will not only need to with retailers and cooperation to improve the service level of the direct sales channels, and how to formulate a reasonable price strategy, good coordination between retailer and interests.

\subsection{Supply Chain Pricing Strategy}

With the rapid development of electronic commerce and pricing problem of dual channel supply chain environment increasingly the attention of scholars at home and abroad, channel structure model has not only contains the traditional single distribution channels, but in the original channel structure model based on, joined the direct channel at this time, manufacturers need not only set the wholesale price to maximize their profits but also to determine the selling price. A large number of research scholars on the problem of dual channel modeling and analysis [7]. Jelassi think traditional retail channels, the seller can interact with the consumers, and consumers can experience products, and then decide whether or not to buy. Therefore, arrived at retail stores and the trial of goods require consumption of consumer time and transportation costs. And retail stores require high cost of investment and the retail time than the direct marketing channels of the store is limited.

On the basis of the assumption that the Druehl has the same requirements, the traditional retail channels and the two channel models with network channels are studied respectively, making use of Nash equilibrium game theory and Stackelberg game theory to set up the optimal price. Park established game theory and competitive structure of pricing model, and mainly discusses the influence of cost and price elasticity coefficient on the equilibrium price [8]. The conclusion shows that the manufacturers through the introduction of direct sales channels and sales prices will reduce demand will increase the overall channel profits will increase and reduce the profits of the retailer. Yao discussed in the dual channel supply chain environment, the manufacturer dominated the Stackelberg competition and the manufacturer and retailer Bertand competitive game model [9]. The pricing strategy under exogenous conditions of wholesale price is studied. The conclusion shows that there exist different wholesale prices under different game model. Cattani discussed three kinds of pricing strategy: the wholesale price unchanged; retail prices unchanged; manufacturer's profit maximization pricing, through numerical analysis found that the three kinds of pricing strategy the first two, at this time, manufacturer and retailer's profit is the largest[10]. Zhang research dual channel environment three most pricing and inventory strategies: retailers occupy a dominant position to set prices; the manufacturer dominates pricing; based on the maximal profit of the supply chain to set prices. The conclusion shows that the total profit of the third strategies is greater than the previous two strategies.

In the dual channel supply chain environment, the manufacturers direct marketing channels in the market share, pricing and profit and other aspects of the existence of competition with the retailer, the formation of channel conflict. Manufacturers as the theme of the dual channel supply chain easily in only the pursuit of the maximization of their own interests, ignoring the interests of the members of other channels, therefore, to avoid double channel conflict and double marginalization effect, manufacturers should take correct cooperation mechanism, the profits due to a reasonable allocation of double marginalization effect and channel members to achieve a win-win situation. Agrawal proposed three based on sales to sensitivity to the needs of coordination mechanism, set up different wholesale prices, and this time to ensure the retailer sales effort, but manufacturers are not guaranteed; second, manufacturers will be part of the service outsourcing to retailers, retailers can get corresponding compensation for services; three is only to provide direct marketing advertising and pre-sales service, retail channels as the ultimate customer purchase channels. The results show that, the last two mechanisms is excellent can effectively alleviate the conflict of dual channel. 


\section{Supply Chain Pricing Model}

\subsection{Model Establishment and Hypothesis}

Dual channel supply chain environment, improve the service level of the direct sales channels and retail channels to increase market share, services mainly include product maintenance and after-sales support, warranty and free shipping, service and constitute the whether consumers to buy the product of an important standard, in the direct sales channels, but the service doesn't have to be done by manufacturers, manufacturers consider retailer service cost advantage, these services to retailers, manufacturers and retailers in dual channel supply chain under the environment of service cooperation between channels. The dual channel type for direct channel is controlled by the manufacturer, in the dual channel, manufacturer's direct sales channels of service outsourcing to retailers, retailers from obtained corresponding remuneration, dual channel service cooperation model, and cooperative model divided into centralized decision mode and decentralized decision-making model. In the decentralized decision-making model, this paper taking the game theory is the foundation of the research, we first study the Bertrand game of manufacturer and retailer's pricing strategy. Then, it studies the manufacturers accounted for a leading position and retailer Stackelberg game service strategy. In this paper, we discuss the pricing model of the manufacturer and retailer's dual channel service cooperation by using the advantage of the low cost of the retailer's service. Variables of the model report: direct sales channels to provide to the level of service to consumers $S_{1}$ and retail channels to provide to the level of service to consumers $\mathrm{S}_{2}$, direct sales channels, product pricing $\mathrm{P}_{1}$, direct sales channels, product pricing $\mathrm{P}_{2}$, direct sales channel for the potential size of the market for $\alpha_{1}$, retail channel the potential size of the market for $\alpha_{2}$, direct channel service cost coefficient $\eta_{1}$, retail channel service cost coefficient $\eta_{2}$, product demand price elasticity coefficient $\lambda_{1}$, the product demand of service of elastic coefficient $\lambda_{2}$.

\subsection{Bertrand Game Pricing Model}

In the dual channel supply chain, when manufacturer and retailer of equal status, manufacturers and retailers of Bertrand game, members is relatively independent, manufacturers direct sales channels of service and retailers to cooperate, at wholesale prices remain unchanged, the order of Bertrand game: 1. To their own profit maximization as the goal, the manufacturer to develop sales channels for direct selling price; 2 . Under unknown direct prices, retailers to their own profit maximization as the goal to develop the retail price of retail channels.

$$
\begin{gathered}
\max _{p_{1}} \Pi_{1}\left(p_{1}, p_{2}\right)=\left(p_{1}-c-\frac{\eta_{1} s_{1}^{2}}{2}\right) q_{1}+(w-c) q_{2} \\
\max \Pi_{p_{2}}\left(p_{1}, p_{2}\right)=\left(p_{2}-w-\frac{\eta_{2} s_{2}^{2}}{2}\right) q_{2}+\left(\frac{\eta_{1} s_{1}^{2}}{2}-\frac{\eta_{2} s_{2}^{2}}{2}\right) q_{1}
\end{gathered}
$$

In the decentralized decision-making model, the manufacturer and the retailer compete for Bertrand, then the optimal pricing:

$$
\begin{array}{r}
p_{1}^{B}=\frac{A_{1} s_{1}^{2}+A_{2} s_{1}+A_{3} s_{2}^{2}+A_{4} s_{2}+A_{5}}{2\left(4 \lambda_{1}^{2}+8 \lambda_{1} \mu_{1}+3 \mu_{1}^{2}\right)} \\
p_{2}^{B}=\frac{A_{6} s_{1}^{2}+A_{7} s_{1}+A_{8} s_{2}^{2}+A_{9} s_{2}+A_{10}}{2\left(4 \lambda_{1}^{2}+8 \lambda_{1} \mu_{1}+3 \mu_{1}^{2}\right)}
\end{array}
$$


The manufacturer's direct selling price is positively related to the service level of the direct selling channel, and the retail price of the retail channel is positively related to the service level of the retail channel.

$$
\begin{gathered}
\frac{\partial P_{1}^{T}}{\partial s_{1}}=\frac{\left(\lambda_{1}+2 u_{1}\right) \lambda_{1} \eta_{2}+\lambda_{1} \lambda_{2}+\lambda_{1} u_{2}+\lambda_{2} u_{1}}{2 \lambda_{1}\left(\lambda_{1}+2 u_{1}\right)}>0 \\
\frac{\partial P_{2}^{T}}{\partial s_{2}}=\frac{\left(\lambda_{2}+2 u_{2}\right) \lambda_{1} \eta_{2}+\lambda_{1} \lambda_{2}+\lambda_{2} u_{1}+\lambda_{1} u_{2}}{2 \lambda_{2}\left(\lambda_{2}+2 u_{2}\right)}>0
\end{gathered}
$$

Effects of direct sales channels for the service level of direct selling price is greater than the impact of retail prices, the effect of the service level of the retail channel of retail price than selling price and selling price and retail price and the direct channel service cost coefficient.

$$
\begin{aligned}
& \frac{\partial P_{1}^{B}}{\partial \eta_{1}}=\frac{\left(4 \lambda_{1} u_{1}+3 u_{1}^{2}+2 \lambda_{1}^{2}\right) s_{1}^{2}}{2\left(4 \lambda_{1}^{2}+8 \lambda_{1} u_{1}+3 u_{1}^{2}\right)}>0 \\
& \frac{\partial P_{2}^{B}}{\partial \eta_{1}}=\frac{3\left(\lambda_{1} u_{1}+u_{1}^{2}\right) s_{1}^{2}}{2\left(4 \lambda_{1}^{2}+8 \lambda_{1} u_{1}+3 u_{1}^{2}\right)}>0
\end{aligned}
$$

Manufacturers in the direct channel service cost coefficient is higher, the higher the retail price.

$$
\frac{\partial P_{2}^{B}}{\partial \eta_{1}}=\frac{3\left(u_{1}+\lambda_{1}\right) u_{1} s_{1}^{2}}{2\left(4 \lambda_{1}^{2}+8 \lambda_{1} u_{1}+3 u_{1}^{2}\right)} \geq 0
$$

\section{Empirical Analysis}

\subsection{The Impact of the Service Level on Prices}

In the dual channel supply chain environment, set up the parameters $\alpha_{1}=240$, $\alpha_{2}=240, \lambda_{1}=6, \lambda_{2}=3.5, \mu_{1}=2, \mu_{2}=1, \eta_{1}=6.5, \eta_{2}=3, c=5, w=10$. The blue curve is Bertrand game environment, the red curve is Stackelberg game environment, the purple curve is under centralized decision environment, circle curve parameters for direct sales channels and starlike curves for the retail channel parameters. Take the retail channel service level $\mathrm{S}_{2}=6$, analysis of the influence of the direct channel service level $S_{1}$ on the channel price.

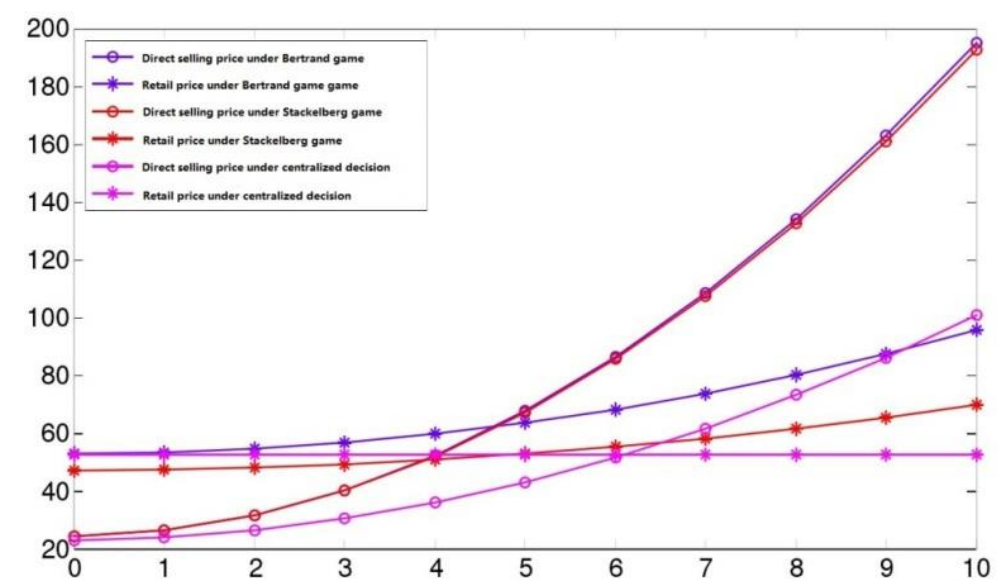

Figure 1. Trends of the Price with the Service in Direct Channel 
From Figure 1 can be seen, with improvement of the direct channel service level, whether it is under Bertrand and Stackelberg game environment or under centralized decision making mode, price channel decreases with the increase in the direct channel service level increased. Conclusion the manufacturer's direct selling price is positively correlated with the service level of the direct selling channel. The price change of the manufacturer's direct channel is relatively large, however, the price of the retail channel is basically not affected by the level of direct channel service. The influence of the service level of the direct selling channel on the direct selling price is higher than that of the retail price. In order to verify the effect of the retail channel service level on the price, the service level of the direct selling channel is $S_{1}=6$, and the effect of $S_{2}$ on the channel price is analyzed.

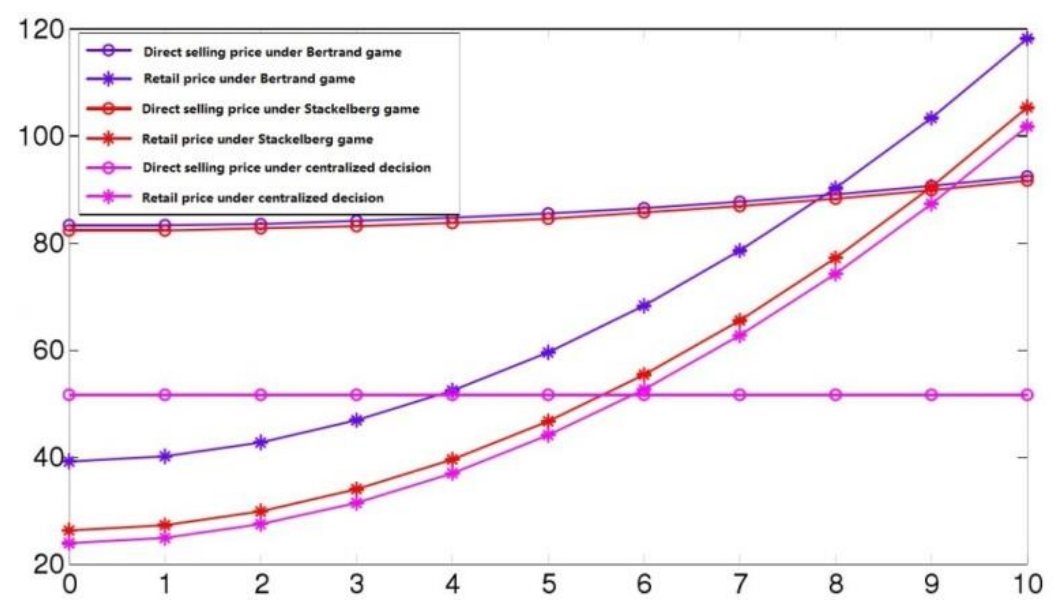

Figure 2. Trends of the Price with the Services in the Retail Channel

From Figure 2, with the improvement of direct channel service level, whether it is under Bertrand and Stackelberg game environment or under centralized decision making mode, price channel decreases with the increase in the direct channel service level increased. The retail price of the retail channel and the service level of the retail channel are positively correlated. In the figure, when changes in the retail channel service level, the magnitude of the price changes of manufacturers of direct sales channels is relatively large, however, the retail channel pricing by the impact of direct channel service level, the effect of the service level of the retail channel of direct selling price is greater than impact on retail price has been verified.

\subsection{Effect of Service Level on Profit}

In the dual channel supply chain environment, set up the parameters $\alpha_{1}=240$, $\alpha_{2}=260, \lambda_{1}=6, \lambda_{2}=3.5, \mu_{1}=2, \mu_{2}=1, \eta_{1}=6.5, \eta_{2}=3, \mathrm{c}=5, \mathrm{w}=10$. Analysis of the impact of direct sales channel service level on the profit, take the retail channel service level $S_{2}=6$, analysis of the influence of the direct channel service level $S_{1}$ on channel profit. 


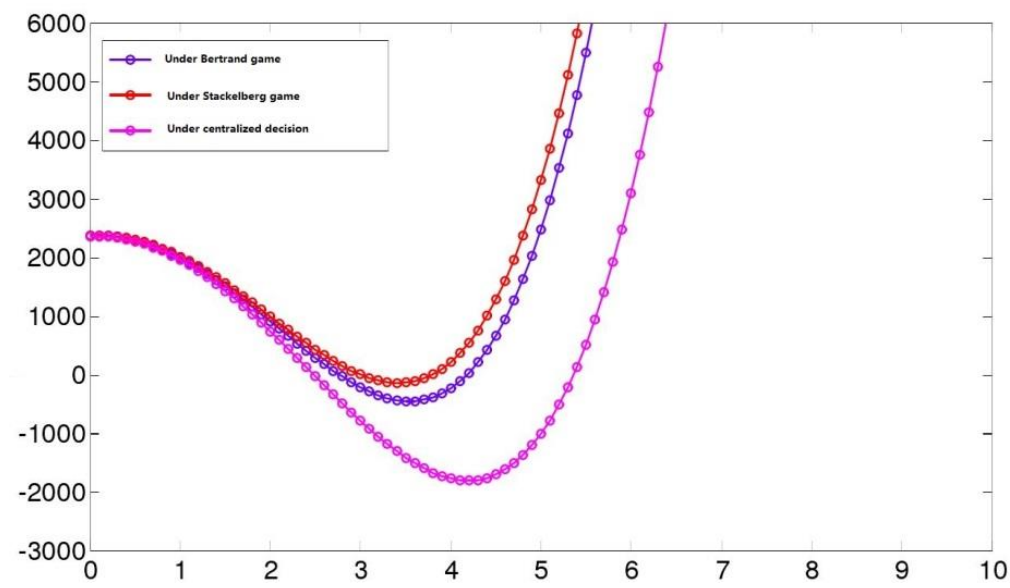

\section{Figure 3. Trends of the Manufacturer's Profit under the different Decision Models}

From Figure 3, we can see that, in different decision-making mode, with the improvement of the level of direct sales channels, the manufacturer's profit first decreased and then increased. Therefore, for dual channel supply chain under the environment of the maker, if direct service channels to retailers complete, requiring retailers provide higher direct channel service level; if the manufacturer to complete their own direct sales channels of service work, you should have a plan to provide lower direct channel service level. As can be seen from Figure 3, manufacturers are willing to choose the Stackelberg game environment and retailers to compete.

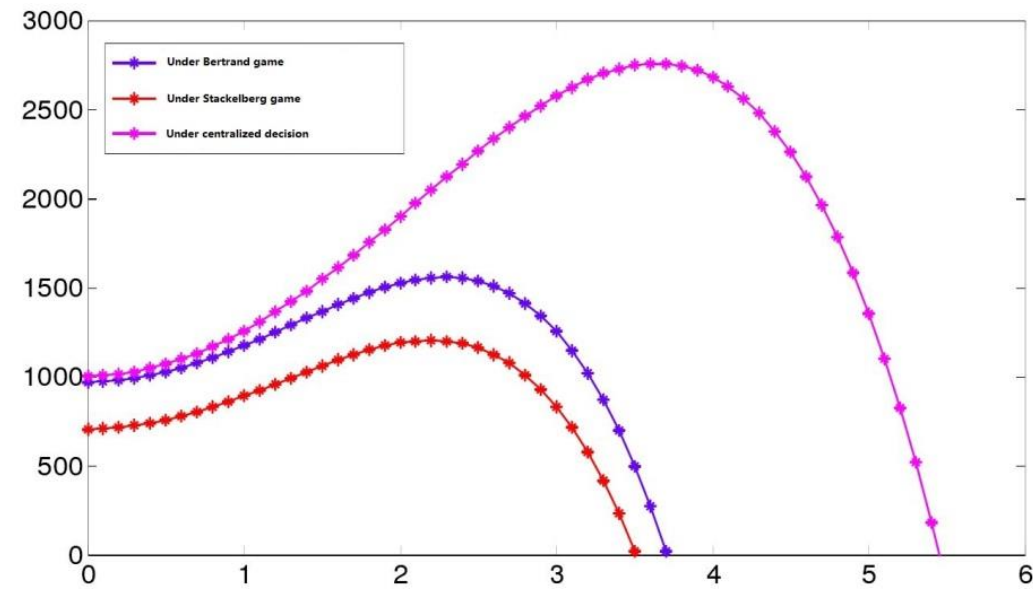

Figure 4. Trends of the Retailer's Profit under the different Decision Models

From Figure 4 we can see that, in different decision-making mode, with the improvement of the level of direct sales channels, the first increase in the profits of retailers to reduce. As can be seen from Figure 4, the retailer is willing to choose the centralized decision-making model to develop the price, if the manufacturer to maintain a competitive relationship, they tend to choose the Bertrand game environment to develop the price.

\subsection{Effect of cost Coefficient on Price}

In the dual channel supply chain environment, set up the parameters $\alpha_{1}=240$, $\alpha_{2}=260, \lambda_{1}=6, \lambda_{2}=3.5, \mu_{1}=2, \mu_{2}=1, s_{1}=6, S_{2}=6, c=5, w=10$. Analysis of effect of direct 
channel service cost coefficient of price, retail channel cost coefficient $\eta_{2}=3$. And analysis of the influence of direct channel service cost coefficient $\eta_{1}$ of direct price and retail price.

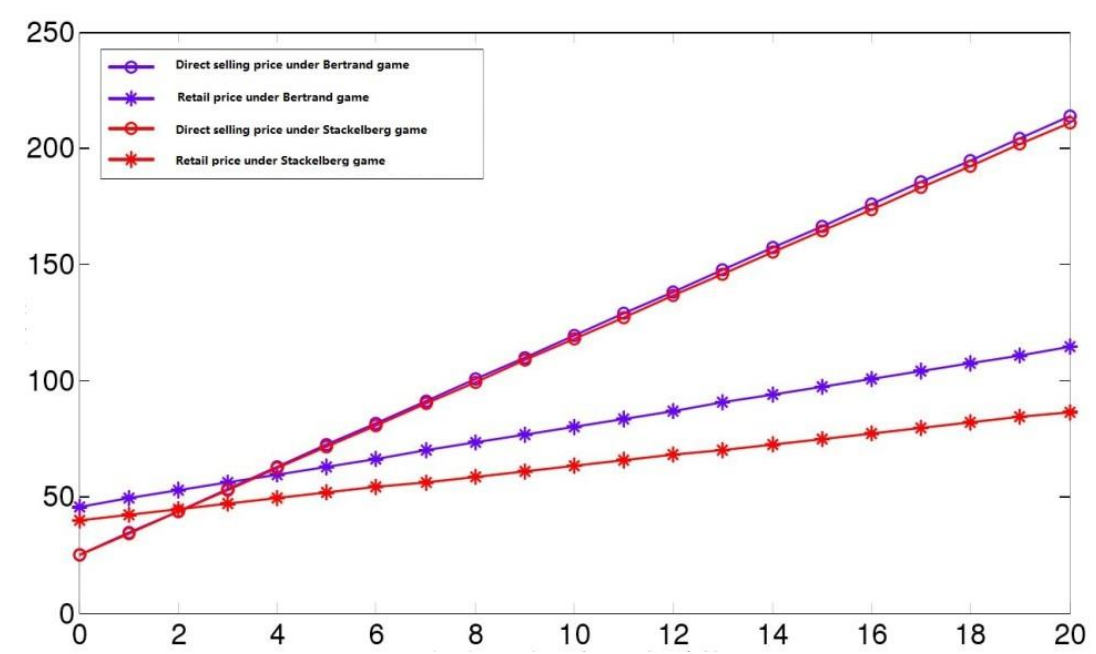

Figure 5. Trends of the Price under different Direct Channel's Cost Coefficients

Figure 5 shows that, whether under Bertrand game or under Stackelberg game, selling price and retail price and the direct channel service cost coefficient is positively correlated, when direct channel service cost coefficient increases, selling price and retail price will improve. Effect of retail channel service cost coefficient on price; take the direct channel service, coefficient $\eta_{1}=6.5$, analysis of the impact of the retail channel service cost coefficient on the price.

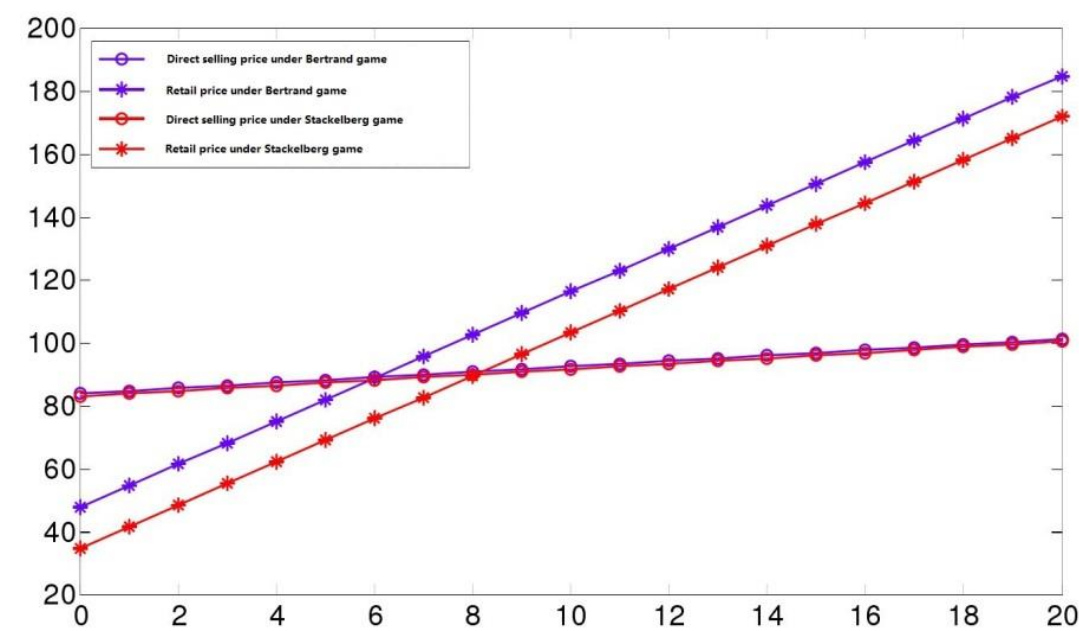

\section{Figure 6. Trends of the Price under different Retail Channel's Cost} Coefficients

As is shown in Fig 6, both in the Bertrand game or under Stackelberg game, when the direct channel service level is lower than the retail channel service level, direct selling price and retail price of all retail channels and service cost coefficient into positive correlation. Pricing models of manufacturers and retailers in decentralized and centralized decision making models, in the decentralized decision-making model, the Bertrand game pricing model and the manufacturer Stackelberg game pricing model are studied 
respectively. Dual channel supply chain pricing strategy, studies have shown that under decentralized control mode, prices and demand for dual channel by the manufacturer in the direct sales channels, the cost of the service and retailers effects in the direct sales channel for the service cost, manufacturers should try to control the direct sales channel for the service cost and service selection and low cost retailer, in order to maintain the competitive advantage of dual channel

\section{Conclusions}

With the development of Internet, more and more companies are introducing direct marketing channels to gain more market share and gain more profits. On the one hand, the service quality of direct marketing channel is the main reason of influencing the market share of direct selling channel. On the other hand, the introduction of direct marketing channels to the retail channel with a competitive pressure, channel pricing and profit distribution became the main cause of the conflict between the two channels. The direct channel service level and retail channels' service level two parameters are introduced to the pricing model of dual channel supply chain, build the leading manufacturer Stackelberg game of supply chain, manufacturers and retailers Bertrand game and centralized decision model of the pricing model, and through model analysis and comparison of different decision environments pricing, manufacturers and retailers should take in service cooperation pricing strategy.

Channel price is positively related to their service level, only by raising the price of direct selling price and the retail price to make up a large number of service costs. In the end, consumers pay for their services". Although manufacturers outsource service to retailers, manufacturers should still need to reduce the cost of direct sales channels. In addition, the manufacturer should choose to cooperate with the lower service cost to maintain the price advantage of the direct selling channel and the retail channel. When the wholesale price is greater than a certain value, can reduce the price of dual channel selection of Stackelberg game, has the advantage of the dual channel to maintain a competitive advantage, if the retailer to improve its own position, manufacturers Bertrand game, you need to raise prices at the expense of; when wholesale prices are higher when manufacturers choose Stackelberg game can increase the demand for direct sales channels, when the wholesale price is low, the choice of Bertrand game can, boosting demand for direct sales channels. Because the manufacturer in the Stackleberg game is always greater than or equal to the profits of the Bertrand game, manufacturers tend to choose the Stakelberg game with the retailer.

\section{Acknowledgements}

This paper is supported by Shanghai Maritime University graduate student $(\mathrm{PhD})$ innovation fund projects (yc2012059).

\section{References}

[1] D. Yao and Q. Liu, "Competitive pricing of mixed retail and e-tail distribution channels", Omega, vol. 33, (2005), pp. 235-247.

[2] A. Enders ad T. Jelassi, "The converging business models of Internet and bricks-and retailers", European Management Journal, vol. 18, (2000), pp. 542-550.

[3] K. Anand, "Context-general and Context-specific Determinants of Online Satisfaction and Loyalty for Commerce and Content Sites", Journal of Interactive Marketing, vol. 24, no. 3, (2010), pp. 222-238.

[4] A. Niklas and S. Fredrik, "Electronic commerce, marketing channels and logistics platform-a wholesaler perspective", European Journal of Operational Research, vol. 144, no. 2, (2003), pp. 270-279.

[5] C. Druehl, E. Porteus, "Price competition between an Internet firm and a bricks and mortar firm", Working Paper, (2001), pp. 24-30.

[6] J. Kim, "The role of etail quality, e-satisfaction and e-trust in online loyalty development process", Journal of Retailing and Consumer Services, vol. 16, no. 4, (2009), pp. 239-247. 
[7] S. Park and H. Keh, "Modeling hybrid distribution channels: a game-theoretic analysis", Journal of Retailing and Consumer Services, vol. 10, (2003), pp. 155-167.

[8] K. Cattani and W. Gilland, "pricing strategies for amanufacturer adding a direct channel that competes with the traditional channel", Productionand Operations Management, vol. 15, (2006), pp. 40-56.

[9] Z. Huang and M. Benyoucef, "From e-commerce to social commerce: A close look at design features", Electronic Commerce Research and Applications, vol. 12, no. 4, (2013), pp. 246-259.

[10] D. Jutla and P. Bodorik, "Developing internet e-commerce benchmarks", Information Systems, vol. 24, no. 6, (1999), pp. 475-493. 